UDC: 811.13(091)

DOI: https://doi.org/10.18485/beoiber.2019.3.1.2

\author{
Ildikó Péter ${ }^{1}$ \\ Doctoranda en la Universidad de Szeged \\ Hungría
}

\title{
¿DEL FUTURUM EXACTUM AL FUTURO DE SUBJUNTIVO ROMANCE? REFLEXIONES A PARTIR DEL GÉNESIS DISCUTIDO DEL FUTURO IMPERFECTO SUBJUNTIVO
}

\begin{abstract}
Resumen
Para el esclarecimiento del origen latino del futuro de subjuntivo romance se han dado diferentes propuestas a lo largo de la historia de la investigación. La que típicamente cuenta con más argumentos a favor es la que ha explicado su antecedente histórico como la confluencia del futuro perfecto de indicativo y el perfecto de subjuntivo, formas de conjugación casi idéntica. Últimamente, se han aducido, sin embargo, buenas razones que prefieren favorecer el futuro perfecto de indicativo como la única forma verbal originaria. Dentro de este marco teórico se sitúa este trabajo, que nos permitirá acercarnos a la esencia misma de las diversas teorías desarrolladas en dicho tema, incluyendo sus méritos y desviaciones, que han dificultado la explicación definitiva del origen latino de la forma verbal cantare.

Palabras clave: futuro de subjuntivo, futuro perfecto de indicativo, confluencia, origen latino.

\section{FROM THE FUTURUM EXACTUM TO THE FUTURE SUBJUNCTIVE ROMANCE? REFLECTIONS ABOUT DISCUSSED GENESIS OF THE FUTURE IMPERFECT SUBJUNCTIVE}

\section{Summary}

Different approaches have been developed throughout the history of research to clarify the Latin origin of the Subjunctive Mood of the Romance languages. The approach that has typically more arguments in favor is the one that has explained the historical antecedent of the subjunctive as the conflation of the future perfect indicative and the perfect subjunctive, forms of almost identical conjugation. Recently, however, convincing arguments have been raised in favor of the future perfect indicative as the only original verbal form. This paper is written within the above-mentioned theoretical framework, which will allow us to get closer to the very essence of the various theories developed in this topic, including its deviations and achievements, which have made difficult the final explanation of the Latin origin of the cantare verb form.
\end{abstract}

Key words: future subjunctive, future perfect indicative, conflation, Latin origin.

\footnotetext{
1 pedrito8517@gmail.com
} 


\section{Introducción}

El objetivo general de este artículo es reflexionar sobre las discrepancias surgidas acerca de la etimología del futuro imperfecto subjuntivo castellano en que -abstracción hecha de la conclusión contundente de Alvar y Pottier (1987: 278) según quienes el problema de los orígenes de la forma verbal cantare ya está resuelto- sigue sin haberse llegado a alcanzar un punto de acuerdo unánime, hecho que justifica la reanalización de este tema, pese a que la bibliografía dedicada a esta cuestión ya es considerada amplia.

Al mismo tiempo, el objetivo concreto del presente estudio es, como se delineará en los siguientes apartados, buscar una explicación actualizada de esta cuestión con el fin de proporcionar una humilde contribución, apoyándose evidentemente en la tesis de Álvarez Rodríguez (2001), a la suposición de que el futuro de subjuntivo ha surgido a partir del futuro perfecto de indicativo ( futurum exactum) sin la intervención del perfecto de subjuntivo latino.

\section{Las diversas hipótesis para explicar el origen del futuro de subjuntivo romance}

En los territorios iberorrománicos ${ }^{2}$ durante el latín hispánico nace un nuevo tiempo verbal, que no existía en latín clásico, que entra en los paradigmas de la conjugación para la expresión del futuro de subjuntivo, forma verbal con plena vigencia en el español medieval y clásico hasta su decadencia documentada a partir del siglo XVI, ${ }^{3}$ que desde el punto de vista diacrónico presenta una evolución bastante compleja y su estudio -especialmente en lo atingente al origen latino- ha dado lugar a más de una explicación. Hasta la fecha, los estudios están en este punto escindidos en cuatro opiniones contrapuestas que se analizará más abajo en más detalle.

\subsection{Del perfecto de subjuntivo latino al futuro de subjuntivo (cantare/- ro<canta(ve)rim)}

La opinión menos apoyada es la de Mohl (1899: 247-248) que sitúa en el perfecto de subjuntivo latino el origen exlusivo del futuro de subjuntivo. Sus argumentos aducidos a favor de esta hipótesis descansan esencialmente en la correspondencia fonética observada entre la forma del perfecto de subjuntivo y la del futuro de subjuntivo del

2 En el portugués actual cantar sigue siendo una forma verbal muy viva, mientras que en el español moderno cantare<cantare/-ro<canta(ve)ro(tcanta(ve)rim) se usa con menos frecuencia, al limitarse solo al lenguaje formal y retórico.

${ }^{3}$ Curiosamente, con respecto a la sustitución de la antigua forma verbal cantare tampoco existe un acuerdo; las posturas se dividen entre los que propugnan que el imperfecto de subjuntivo cantase tendía a ocupar el puesto del futuro de subjuntivo (cf. Cano Aguilar 1988) y los que optan por el presente de subjuntivo e indicativo cante/canto como continuadores históricos de dicho tiempo (cf. Veiga 1989). 
español clásico, pero, al mismo tiempo, se pierde de vista la diacronía de la desinencia medieval -o de primera persona del tipo cantaro, que aparece con relativa frecuencia en los textos medievales, ${ }^{4}$ hecho que ha supuesto una buena razón para desestimar esta tesis.

\subsection{Tesis de la triple fusión (cantare/-ro<canta(ve)rim+cantarem+canta(ve)ro)}

La segunda opinión digna de reseña es la de los autores (Wright 1931: 107; Marcos Marín 1979: 92; Lloyd 1989: 311; Porcar 1993: 98-100; Andres-Suárez 1994: 115-117; Macías 1997: 471) que propugnan una confluencia triple. A su entender, desde el perfecto de subjuntivo, el futuro perfecto de indicativo y el imperfecto de subjuntivo - tras producirse la síncopa en las formas de perfecto y como consecuencia de la proximidad semántica entre los conceptos de irrealidad, posibilidad y eventualidad - se crea en latín hispánico el futuro de subjuntivo, que no existía en latín clásico. Concuerda con esta argumentación lo que dice Ridruejo, quien propone la siguiente relación aparentemente lógica:

Como consecuencia de la evolución fónica de las marcas pudieron producirse homonimias totales o parciales que, no salvadas, conllevaron la pérdida de oposiciones funcionales. Probablemente esto es lo que sucedió en la fusión de AMAVERIM, AMAVERO y quizá AMAREM, dando lugar al denominado futuro de subjuntivo del español (amare), que hereda alguna de las funciones fundidas. (Ridruejo 1996: 525-526)

Su propuesta resulta, sin embargo, discutible al demostrarse que la coincidencia con el imperfecto de subjuntivo latino es tan solo una coincidencia de superficie, puesto que en varias formas del castellano antiguo se ve bien reflejado que el futuro de subjuntivo deriva del tema de perfecto y no del tema de infectum. ${ }^{5}$ Además, de acuerdo con los datos aportados por Garrido Sepúlveda (2017: 96) "la significación modotemporal originaria del futuro de subjuntivo fue siempre no irreal (SUBJ 0) en orientación temporal de presente y futuro, de manera que el valor irreal (SUBJ 2) de amarem y su valor no irreal (SUBJ 0) en orientación de copretérito tampoco explicarían la semántica de amare."

Tradicionalmente, como se verá más abajo en más detalle, se defiende que son dos paradigmas latinos casi idénticos de los que puede derivar la forma romance en cuestión:

${ }^{4}$ Hay que citar aquí a Menéndez Pidal (1976 §92.4), quien apunta que hasta el siglo XIV la desinencia - o para la primera persona del futuro de subjuntivo utuvo tal vitalidad, que hasta produjo en el dialecto de la Bureba una forma analógica en la primera persona del pluscuamperfecto latino o imperfecto romance (quisiesso, ouiesso)."

${ }^{5}$ Se necesita observar que el tema de infectum solo sería válido en el caso de los verbos regulares, no explicaría, sin embargo, los irregulares. Tal como indica Álvarez (2001: 22), la convergencia fonética de amares y ama(ve)ris es posible, pero no lo es en el caso de diceres y dixeris. 
el futuro perfecto de indicativo o futurum exactum ${ }^{6}$ (canta(ve)ro) y el pretérito perfecto de subjuntivo (canta(ve)rim). La opinión de algunos estudiosos, generalmente detractores de esta tesis fusionista, pronto se rebeló contra esta argumentación. Así, entre otros, Álvarez Rodríguez (2001: 85) al continuar la línea dieziana ${ }^{7}$ sostiene que el antecedente histórico de la forma cantare se halla solo y exclusivamente en el futuro perfecto de indicativo, de ahí que al respecto no sea preciso hablar de alguna fusión.

\subsection{Tesis fusionista (cantare/-ro < canta(ve)ro+canta(ve)rim)}

Al hablar de la etimología del futuro de subjuntivo romance, constituye un aserto aceptado generalmente en las gramáticas históricas del español la fusión entre los paradigmas de canta(ve)ro y canta(ve)rim iniciada por la casi identidad formal de esos dos tiempos latinos -excepto en la primer persona del singular y tercera del plural-, por una parte, y por la proximidad semántica supuesta en algunos tipos oracionales (condicionales, relativas, temporales), en los que justo por la coincidencia morfológica es bastante difícil determinar si sus formas verbales son futuro perfecto de indicativo o perfecto de subjuntivo.

Los autores como Lausberg (1962: §827), Väänänen (1963: §307), Alvar y Pottier (1983: §174.2), Lathrop (1985: 76), Cano Aguilar (1988: 161), Veiga (1989: 257), Penny (1998: 199), Lapesa (2000: 719), Berta (2003: 47), Azofra (2009: 97), entre otros, que defienden la teoría fusionista, ven justificada, como prueba a favor de la misma, la alternancia observada entre las formas en -e (cantare) y formas en -o (cantaro) en la primera persona del singular en los textos medievales 8 que se debe a la confluencia por la que el antecedente latino abandonaría la desinencia -im del perfecto de subjuntivo adoptando la terminación - o del futuro perfecto de indicativo. El problema principal de este procedimiento es que, al analizar la diacronía de la forma de primera persona del futuro de subjuntivo, las formas en - $e$ no necesariamente pueden ser interpretadas como la continuación de la desinencia -im derivada de canta(ve)rim, ${ }^{9}$ tal como consideran los fusionistas, sino que prefiere suponerse como el producto del influjo analógico de las otras personas e incluso del imperfecto de subjuntivo, que comparte con el futuro el mismo tema verbal que tiene - e en todas las personas. Concuerda con estos datos lo que apunta García de Diego, quien entiende la forma cantare como una reconstrucción analógica sobre un cantar procedente de apócope de - $O$ en cantaro: "Sobre las formas a mavero etc., se formó el futuro amaro amar mod. amare, etc..[...] esta terminación en -re, analógica de las demás personas, acabó por prevalecer en el siglo XIV, al fin del cual

${ }^{6}$ Conocido también como futuro II (cf. Väänänen 1968: 215).

7 Para la primera opinión favorable al futurum exactum véase F. Diez (1858: 160).

8 Se documenta que a partir del siglo XIII el triunfo de la variante -ere está generalizado en detrimento de -ero.

${ }^{9}$ Lausberg (1962: §827) llega a la constatación de que "formalmente ocurre clarísimamente una fusión del futurum exactum latino con el subjuntivo perfecto latino, como prueban las dobles formas de la 1. ${ }^{a}$ pers._-Latín dé de ri m da, previa la forma disimilada (§ 825) "dę eri, esp. diere, port. der." 
son raras ya las formas en -ro" (García de Diego 1981: 231). En vista de lo anterior, se debe suponer, por lo tanto, que de las formas terminadas en - 0 , la desinencia es etimológica, mientras que la -e, con toda probabilidad, es consecuencia analógica.

\subsection{Del futurum exactum al futuro de subjuntivo romance (cantare/-ro<canta(ve)ro)}

Por lo que hemos visto hasta ahora, últimamente los estudiosos parecen inclinarse cada vez más por rechazar la susodicha conjetura fusionista al retomar la antigua de Diez. ${ }^{10}$

El único problema que parece cuestionar la hipótesis dieziana de que el futuro perfecto de indicativo se registre como el único antecedente histórico del futuro de subjuntivo romance se vincula con el hecho de que en cantare confluyen un valor temporal futuro con el contenido modal subjuntivo. Al respecto, por un lado, Álvarez Rodríguez (2001: 66) llega a la conclusión de que desde el Satiricón los futuros perfectos pasivos sustituyeron la forma auxiliar ero por fuero en las proposiciones subordinadas frente al perfecto de subjuntivo pasivo que se construía siempre con sim (no fuerim), de ahí que las formas amatus fueris, -it, -imus, -itis, -int ya no pueden ser interpretadas como formas pasivas de perfecto de subjuntivo, pese a la aparente coincidencia morfológica, sino de futurum exactum. Esta transformación, a su entender, fue hecho crucial que devino en su proceso de plena subjuntivización. ${ }^{11}$ Por otro lado, refuerza su susodicha hipótesis también el hecho de que la mayoría de gramáticos posteriores a esta época (Carisio, Diomedes, Prisciano, Probo, Donato, Servio, Cledonio, Pompeyo, Consencio, San Agustín, Mario Plocio, etc.) adscriben el futuro perfecto al modo subjuntivo. ${ }^{12}$

Evidentemente, se desprende (del amplio corpus bien elaborado del mismo autor [Álvarez Rodríguez 2001: 29-54], que ofrece la ventaja de pertenecer a diferentes etapas de la historia del latín, en las que el futuro perfecto mantenía una vigencia importante que en determinados tipos de cláusulas subordinadas, principalmente en las condicionales, contextos ${ }^{13}$ a los que límita su uso mayoritario desde sus orígenes el futuro de subjuntivo también), el futurum exactum ya en el latín tardío y luego en el medieval habría experimentado un reajuste temporal y modal, por el que comenzó a expresar

10 La procedencia del futuro imperfecto subjuntivo a partir del futurum exactum fue tesis sostenida, entre otros, por Meyer Lübke (1894: 354), Menéndez Pidal (1940: 313-314), Hanssen (1945: 241) o Bassols De Climent (1956: 306).

${ }^{11}$ En este punto se precisa senalar que según Álvarez (2001: 67), probablemente por analogía de las formas pasivas, las activas del futurum exactum también se distancian del modo indicativo y se sienten ya como subjuntivos, mientras que los futura exacta activos continúan adscritos al indicativo.

12 Para esta última conclusión, cf. Álvarez Rodríguez (2001: 67).

13 Recordando una vez más a Lausberg (1962: §827) se postula que desde el punto de vista semántico el futuro imperfecto subjuntivo debe interpretarse como continuador de la función del futurum exactum en las oraciones secundarias. 
subjetividad, y tras perder su valor habitual de anterioridad adquirió un valor simplemente de futuro, de ahí que pasara a referirse a una acción presente o presentefutura, indicando simultaneidad con la principal, al igual que se observa en el caso de su posterior continuador histórico, el futuro de subjuntivo, que llega a expresar el mismo valor (SUBJ 0-no irreal) ${ }^{14}$ que se atribuía al presente de subjuntivo en el latín clásico, de este modo en el antiguo español cantare y cante ya coinciden ambas formas, por tanto, tal como lo interpreta Veiga (2006: 156), están en "visible distribución complementaria".

En vista de lo anterior se ve que el peso de la atención ha recaído mayoritariamente sobre la compleja transformación de las formas del futurum exactum que concluyó en la adquisición del valor modal subjuntivo (no irreal) y del valor temporal presente-futuro en el paso a las lenguas romances. Interesa, sin embargo, echar un rápido vistazo también a la evolución y transformación que experimentó el perfecto de subjuntivo, como posible participante en la formación del futuro de subjuntivo junto con el citado futuro de indicativo, según la tesis fusionista. Partiendo de la observación advertida por Álvarez Rodríguez (2001: 63), según quien como expresión de la eventualidad, las formas del perfecto de subjuntivo siempre fueron de uso minoritario a lo largo de la historia del latín, parece conveniente tener en consideración otros factores que pueden validar dicha conjetura.

Suele ocurrir que dos elementos al desempeñar la misma función representan una redundancia que puede ser corregida mediante la eliminación de uno de ellos, normalmente el más marcado o el menos frecuente. En nuestro caso las formas cantarem y canta(ve)rim por ser menos frecuentes eran las que muy temprano cayeron en desuso, de modo que el pluscuamperfecto de subjuntivo latino ${ }^{15}$ (canta(vi)ssem) comenzó a emplearse tanto para indicar la irrealidad como la potencialidad, según observa Herman (1997: 112-113):

Puede suceder incluso que el pluscuamperfecto se emplee en lugar del perfecto (este último expresaba la anterioridad tras el presente de la principal): increpant nobis hic haeretici cur scriptura sancta Dominum dixissit (Gregorio de Tours, Historia Francorum, I, 4) [...] las particularidades sintácticas que acabamos de señalar prueban que esta conservación fue consecuencia, junto a factores formales, de desplazamientos funcionales, ya en curso en el latín tardío vulgar, que se operaron en detrimento de formas como cantarem, cantauerim, condenadas a desaparecer.

Concuerda con estos datos lo que dice el fusionista Väänänen (1968: 216-217) al referirse al pluscuamperfecto de subjuntivo, que utiende a ocupar el puesto del imperfecto y del perfecto, que en la pronunciación podían ser confundidos: cantarem, -es, etc., y

14 Según observa Garrido Sepúlveda (2017: 79) «el subjuntivo 0 se caracteriza por presentar matices de subjetividad o de conocimiento inconcreto y corresponde a la unidad de contenido modal no marcado (0) entre las unidades del modo subjuntivo."

15 Probablemente por ser más caracterizado y más expresivo por su terminación en -ss-, y más "fuerte" desde el punto de vista fonético (cf. Herman 1997: 112). 
canta(ve)rim, -is, etc.:". Mohl (1899: 248) muestra una opinión muy parecida a este respecto al hacer alusión explícita a que el perfecto del subjuntivo parece amenazado de muerte ya en el momento en que se escribieron el Bellum Africanum y el Bellum Hispaniense, amenazado de muerte como el imperfecto del mismo modo, en ambos casos en beneficio del pluscuamperfecto de subjuntivo.

Dado que el pretérito pluscuamperfecto de subjuntivo latino ${ }^{16}$ acabó absorbiendo en un primer momento todos los empleos del imperfecto de subjuntivo latino $y$ posteriormente también los del perfecto de subjuntivo, el hecho de que el futuro perfecto de indicativo se haya combinado con el formalmente casi idéntico pretérito de subjuntivo para dar origen al futuro de subjuntivo español puede considerarse como contradictorio. La teoría que acabamos de exponer proporcionaría una explicación suplementaria para probar que el antepasado latino del futuro de subjuntivo frente a la tesis fusionista reside únicamente en el futurum exactum.

\section{Observaciones finales}

Resumiendo lo arriba expuesto se puede afirmar que de las tres formas de la conjugación latina (canta(ve)ro, canta(ve)rim y cantarem) que se postulan como posibles precedentes del futuro imperfecto subjuntivo, se han desarrollado cuatro hipótesis por lo que atañe a la génesis de dicho tiempo verbal: la tesis del perfecto de subjuntivo como origen único del futuro de subjuntivo (la de Mohl) pronto ha sido relegada por no hacer mención alguna a la terminación medieval - 0 de primera persona; la tesis de la confluencia triple se sustenta en asertos morfológica y semánticamente incorrectos. Aunque la mayor cantidad de estudiosos parece apostar más por una confluencia entre el futuro perfecto y el perfecto de subjuntivo motivada por un alomorfismo de todas las personas salvo de la primera, coincidencias formales que aparentemente parecen dificultar el establecimiento del origen latino concreto de la forma verbal cantare, esta conjetura también se ve contradicha, como ya fue explicado, por la diacronía del perfecto de subjuntivo y de la desinencia -o medieval. Todas estas observaciones llevadas a cabo en el presente estudio son lo suficientemente significativas como para reforzar la hipótesis de que explicar la etimología del futuro de subjuntivo romance con la opción del futurum exactum solo, resulta simple y más que razonable.

16 El préterito plucuamperfecto de subjuntivo latino cantavissem dio origen al imperfecto de subjuntivo español cantase. 


\section{BIBLIOGRAFÍA}

Alvar, Manuel, y Bernard Pottier. Morfología histórica del español. Madrid: Gredos, 1987. Impreso.

Álvarez Rodríguez, Adelino. El futuro de subjuntivo. Del latín al romance. Málaga: Universidad de Málaga, 2001. Impreso.

Andrés-Suárez, Irene. El verbo español: sistemas medievales y sistema clásico. Madrid: Gredos, 1994. Impreso.

Azofra Sierra, María Elena. Morfosintaxis histórica del español: de la teoría a la práctica. Madrid: Universidad Nacional de Educación a Distancia, 2009. Web. 27 Nov. 2018.

Bassols De Climent, M. Sintaxis latina I. 2 vols. Madrid: Consejo Superior de Investigaciones Científicas, 1956. Impreso

Berta, Tibor. Clíticos e Infinitivo. Szeged: Hispánia, 2003. Impreso.

Cano Aguilar, Rafael. El español a través de los tiempos. Madrid: Arco/Libros, 1988. Impreso.

Diez, Friedrich. Grammatik der romanischen Sprachen. 2a parte. Bonn: Weber, 1858. Web. 02. Nov. 2018.

García de Diego, Vicente. Gramática histórica española. Madrid: Gredos, 1981. Impreso.

Garrido Sepúlveda, Claudio. La expresión de la condicionalidad en los romanceamientos bíblicos medievales. Tesis doctoral. Universidad Autónoma de Barcelona, 2017. Web. 18 Nov. 2018.

Hanssen, Federico. Gramática histórica de la lengua castellana. Buenos Aires: El Ateneo, 1945. Impreso.

Herman, József. El latín vulgar. Barcelona: Editorial Ariel, S.A., 1997. Impreso.

Lapesa, Rafael. Estudios de morfosintaxis histórica del español. Morfosintaxis histórica del verbo español. Ed. de Rafael Cano Aguilar y Mª T. Echenique Elizondo. II. Madrid: Editorial Gredos, 2000. Impreso.

Lathrop, Thomas A. Curso de gramática histórica española. Barcelona: Editorial Ariel, S. A., 1985. Impreso.

Lausberg, Heinrich. Lingüistica románica, Il. Morfología. Madrid: Gredos, 1966. Impreso.

Lloyd, Paul M. From Latin to Spanish: Historical Phonology of the Spanish Language. I. Filadelfia: American Philosophical Society, 1989. Print.

Macías, Cristóbal. "La oración condicional: del latín al español." Analecta Malacitana, 20.2 (1997): 447-474. Web. 20 Oct. 2018.

Marcos Marín, Francisco. "Observaciones sobre las construcciones condicionales en la historia de la lengua española," Nueva Revista de Filología Hispánica, 28.1 (1979): 86-105. Web. 19 Nov. 2018.

Menéndez Pidal, Ramón. Manual de Gramática histórica española. Madrid: Espasa-Calpe, 1940. Impreso. 
- Cantar de Mio Cid. Texto, gramática y vocabulario. I. 5a edición. Madrid: EspasaCalpe, 1976. Web. 04 Dic 2018.

Meyer-Lübke, Wilhelm. Grammatik der romanischen Sprachen. Leipzig: O. R. Reisland, 1894. Web. 24 Nov. 2018.

Mohl, Friedrich Georg. Introduction à la chronologie du latin vulgaire. Étude de philologie historique. París: Bouillon, 1899. Web. 02 Déc. 2018.

Penny, Ralph. Gramática histórica del español. Barcelona: Editorial Ariel, S.A., 1998. Impreso.

Porcar, Margarita. La oración condicional: La evolución de los esquemas verbales condicionales desde el latín al español actual. Valencia: Universitat Jaume I., 1993. Impreso.

Ridruejo, Emilio. "Sobre el origen de los futuros románicos". Actas del III Congreso Internacional de Historia de la lengua española. Madrid: Arco-Libros, 1996: 525533. Impreso.

Veiga, Alexandre. "La sustitución del futuro de subjuntivo en la diacronía del verbo español." Verba. Anuario Galego de Filoloxía, 16 (1989): 257-338. Web. 12 Dic. 2018.

-. "Las formas verbales subjuntivas. Su reorganización modo-temporal." Concepción Company (ed.), Sintaxis histórica de la lengua española. Primera parte: La frase verbal, México D.F.: Fondo de Cultura Económica, (2006): 93-240. Web. 27 Nov. 2018.

Väänänen, Veiko. Introducción al latín vulgar. Madrid: Gredos, 1968. Impreso.

Wright, L. O. "The disappearing Spanish verb form in -re." Hispania, XIV (1931): 107-114. Web. 14 Oct. 2018. 